\title{
Downregulation of KLF4 activates embryonic and fetal globin mRNA expression in human erythroid progenitor cells
}

\author{
PINYAPHAT KHAMPHIKHAM ${ }^{1,2}$, NATEE JEARAWIRIYAPAISARN ${ }^{3}$, \\ AMORNRAT TANGPRASITTIPAP ${ }^{4}$ and SURADEJ HONGENG ${ }^{5}$ \\ ${ }^{1}$ Department of Forensic Science, Faculty of Allied Health Sciences, Thammasat University, Pathum Thani 12121; \\ ${ }^{2}$ Division of Clinical Microscopy, Department of Medical Technology, Faculty of Associated Medical Sciences, \\ Chiang Mai University, Chiang Mai 50200; ${ }^{3}$ Thalassemia Research Center, Institute of Molecular Biosciences, \\ Mahidol University, Nakhon Pathom 73170; ${ }^{4}$ Office of Research, Academic Affairs and Innovations and \\ ${ }^{5}$ Department of Pediatrics, Faculty of Medicine, Ramathibodi Hospital, Mahidol University, Bangkok 10400, Thailand
}

Received January 28, 2021; Accepted May 14, 2021

DOI: $10.3892 /$ etm.2021.10539

\begin{abstract}
The Krüppel-like factor (KLF) family dominates highly conserved three zinc finger DNA binding domains at the $\mathrm{C}$-terminus and variable transactivation domains at the $\mathrm{N}$-terminus. Humans possess $18 K L F$ genes that are differentially expressed in various tissues. Several KLFs recognize a specific CACCC DNA motif that is commonly found within hematopoietic-specific promoters. To investigate those KLFs that are involved in human hemoglobin $(\mathrm{Hb})$ switching, the present study analyzed a previous microarray data set from fetal and adult erythroid cells and validated the mRNA expression levels of $18 K L F$ s by reverse transcription-quantitative PCR (RT-qPCR). KLF with a decreased expression level in the fetuses was selected for a functional study in human erythroid progenitor cells using lentiviral-based short hairpin RNA knockdown. The fetuses demonstrated a lower level of KLF4 mRNA expression when compared with the adults. Downregulation of KLF4 in erythroid progenitor cells from healthy individuals and individuals with $\beta^{0}$-thalassemia/ $\mathrm{HbE}$ evidenced the increasing embryonic and fetal globin mRNA expression with neither significant cytotoxicity nor gene expression alteration of the examined globin regulators, KLF1, B-cell lymphoma/leukemia 11 A and lymphoma/leukemia-related factor. These findings demonstrate that the downregulation of KLF4 is associated with increased embryonic and fetal globin gene expression in human erythroid progenitor cells. Moreover, identifying putative compounds or molecular approaches that effectively downregulate KLF4 and further induce embryonic
\end{abstract}

Correspondence to: Dr Pinyaphat Khamphikham, Division of Clinical Microscopy, Department of Medical Technology, Faculty of Associated Medical Sciences, Chiang Mai University, 110 Intawaroros Road, Sripoom, Chiang Mai 50200, Thailand E-mail: pinyaphat.kha@cmu.ac.th

Key words: Krüppel-like factor 4, embryonic globin, fetal globin globin expression may provide an alternative therapeutic strategy for $\alpha$-globin substitution in severe $\alpha$-thalassemia.

\section{Introduction}

Fetal hemoglobin $\left(\alpha_{2} \gamma_{2}\right.$; also termed $\left.\mathrm{HbF}\right)$ to adult $\mathrm{Hb}\left(\alpha_{2} \beta_{2}\right.$; also termed $\mathrm{HbA}$ ) switching is usually completed within one year after birth and results in a normal $\mathrm{Hb}$ profile in adulthood, comprising $\mathrm{HbF}(<1 \%), \mathrm{HbA}_{2}\left(\alpha_{2} \delta_{2} ; 2-3 \%\right)$ and $\mathrm{HbA}(\geq 95 \%)$ (1). This obscure scheme is controlled by many zinc finger transcription factors, such as Krüppel-like factor 1 (KLF1) (2), B-cell lymphoma/leukemia 11A (BCL11A) (3) and leukemia/lymphoma-related factor (LRF) (4). KLF1 is known as an erythroid-specific transcription factor that orchestrates the expression of hundreds of erythroid essential genes, including fetal and adult globin genes $(2,5)$. KLF1 regulates fetal to adult $\mathrm{Hb}$ switching by direct activation of $\beta$-globin $(H B B)$ gene expression and indirect repression of the $\gamma$-globin $(H B G)$ gene by stimulating the expression of BCL11A and LRF, two major $H B G$ gene repressors $(6,7)$. Furthermore, the docking of KLF1 on the CACCC core box within $H B B, B C L 11 A$ and $L R F$ promoters was mentioned as an initial step of gene expression (6,7). Downregulation of KLF1 reduces BCL11A expression and further increases $H B G$ gene and $\mathrm{HbF}$ production $(2,7)$. In addition, KLF1 occupies the $L R F$ promoter in human erythroid cells and activates $L R F$ gene expression (6). KLF1 is categorized as a member of the KLF family. To date, $18 K L F$ genes have been described in human chromosomes $(8,9)$. KLF members are characterized by three $\mathrm{Cys}_{2} \mathrm{His}_{2}$ zinc finger DNA binding domains at the $\mathrm{C}$-terminus, and variable transactivating domains at the N-terminus. The binding domains of KLFs recognize specific DNA motifs containing GC-rich or CACCC boxes, whereas the transactivating domains harness transcriptional levels of the target genes upon which co-activators or co-repressors are recruited (10). Notably, the CACCC motif has been identified as a common regulatory element in erythroid gene promoters, particularly in globin gene promoters $(6,11,12)$. 
Furthermore, KLF1 amino acid sequences have the highest homology with KLF2 and KLF4 (13). KLF2 (or lung KLF) regulates embryonic globin gene expression and is essential for erythroid maturation within the yolk sac in transgenic mice $(14,15)$. KLF4 (or gut KLF) binds to the CACCC motif within the $H B G$ gene promoter and activates $H B G$ gene expression in early erythroid progenitor cells from adults (16). Additionally, KLF4 is able to dock on the $\alpha$-globin $(H B A)$ gene promoter and stimulate the gene expression in the human chronic myeloid leukemia (K562) cell line (17). In zebrafish, klf4 acts as an embryonic globin gene suppressor; however, the arrangement of globin genes in zebrafish differs from that of humans (18).

The present study proposed that additional KLF members may be crucial for human globin gene regulation in erythroid cells. To ascertain a potential for KLF in exploiting globin gene regulation, the mRNA expression of $18 \mathrm{KLFs}$ in erythroid progenitor cells from fetal liver and adult peripheral blood samples were screened for their relative differences in terms of the globin gene expression status at specific developmental stages. $K L F$ with the greatest decrease of mRNA expression in the fetus was chosen for a functional study using RNA interference in adult peripheral blood-derived erythroid progenitor cells. Effects of $K L F$ knockdown during in vitro erythropoiesis were assessed. Reactivation of embryonic or fetal globin gene expression after the $K L F$ knockdown was investigated. These changes in globin gene expression can be exploited for potential therapeutic implications for severe thalassemias in which a specific globin gene was insufficient.

\section{Materials and methods}

Samples. Existing cDNA samples from a previous microarray study (19) were used as templates for investigating $K L F$ expression patterns in the present study. The cDNA samples were prepared from the RNA of hematopoietic progenitor cells from fetal liver samples $(n=3)$ and adult peripheral blood samples $(n=3)$. Whole blood samples were drawn from six adults who were aged $\geq 18$ years, consisting of healthy volunteers (50 ml; $\mathrm{n}=3$ ) and patients with $\beta^{0}$-thalassemia/HbE $(25 \mathrm{ml} ; \mathrm{n}=3)$ at Faculty of Allied Health Sciences, Thammasat University (Pathum Thani, Thailand) in June 2020 after obtaining written informed consent. Anticoagulant Citrate Dextrose Solution, Solution A (Terumo Bct, Inc.) was used as a preservative. Thalassemia and other hemoglobinopathies were ruled out in the healthy subjects. The most common deletional $\alpha$-thalassemia mutations, including- $\alpha^{3.7},-\alpha^{4.2}$, -- SEA and --_HAI were screened for exclusion, and $H B B$ genes were genotyped in the subjects with $\beta^{0}$-thalassemia/HbE. At the time of sampling, the patients had not received any blood transfusions for $\geq 1$ month before venipuncture. All hematological parameters and $\mathrm{Hb}$ typing were obtained from an automated blood cell analyzer (ADVIA 2120; Bayer AG) and the VARIANT II $\beta$-thalassemia Short Program (Bio-Rad Laboratories, Inc.), respectively. The hematological data of the subjects are presented in Table SI.

Erythroblast culture. Peripheral blood mononuclear cells (PBMCs) were immediately harvested from the blood samples using Lymphoprep (Axis-Shield). Hematopoietic stem cells or progenitor cells $\left(\mathrm{CD}_{34}{ }^{+}\right)$were purified from the PBMCs using a CD34 MicroBead Kit (Miltenyi Biotec $\mathrm{GmbH}$ ) with a magnetic activated cell sorting column according to the manufacturer's instructions. The isolated CD $34^{+}$cells were placed in the 3-phase erythroblast culture system where the cells were able to grow, expand and differentiate into erythroid cells. Briefly, Iscove's modified Dulbecco's medium (Biochrom $\mathrm{GmbH}$ ) supplemented with $20 \%$ v/v fetal bovine serum (FBS; EMD Millipore), $300 \mu \mathrm{g} / \mathrm{ml}$ holo-transferrin (ProSpec-Tany TechnoGene Ltd.) and 1\% v/v penicillin/streptomycin (Gibco; Thermo Fisher Scientific, Inc.) was prepared as a basal medium. In phase 1 (days 0-4), the basal medium was augmented with $10 \mathrm{ng} / \mathrm{ml}$ human interleukin-3 (IL-3; Miltenyi Biotec $\mathrm{GmbH}$ ), $50 \mathrm{ng} / \mathrm{ml}$ human stem cell factor (SCF; Miltenyi Biotec $\mathrm{GmbH}$ ) and $2 \mathrm{U} / \mathrm{ml}$ erythropoietin (EPO; Janssen-Cilag Ltd.). In phase 2 (days 4-8), the basal medium was fortified by $10 \mathrm{ng} / \mathrm{ml} \mathrm{SCF}$ and $2 \mathrm{U} / \mathrm{ml}$ EPO. In phase 3 (days 8-14), the basal medium was only supplemented with $4 \mathrm{U} / \mathrm{ml}$ EPO. As the number of isolated CD $34^{+}$cells varied among individuals, cell numbers were reserved at $1-2 \times 10^{6}$ cells $/ \mathrm{ml}$ during the culture. The cells were incubated at $37^{\circ} \mathrm{C}$ in a $5 \% \mathrm{CO}_{2}$ and $100 \%$ humidity atmosphere.

KLF4 knockdown. KLF4sh1 (cat. no. TRCN0000231078) and KLF4sh2 (cat. no. TRCN0000231079) short hairpin (sh)RNA sequences were obtained from the MISSION ${ }^{\circledR}$ shRNA library (Sigma-Aldrich; Merck KGaA; https://www.sigmaaldrich. com/catalog/genes/KLF4?lang=en\&region=GB\#shRNA\%20 Products) and cloned into the third-generation lentiviral vector, pLL3.7-puro, containing the mouse U6 promoter for driving shRNA expression and the puromycin resistance gene as a selectable marker. pLL3.7-puro was in-house modified from pLL3.7 (cat. no. 11795; Addgene, Inc.) by replacing the EGFP gene with the puromycin resistant gene. The 293T cells (cat. no. CRL-3216; American Type Culture Collection) were cultured in Dulbecco's modified Eagle's medium (Gibco; Thermo Fisher Scientific, Inc.) supplemented with $10 \%$ v/v FBS and 2 mM L-glutamine (Gibco; Thermo Fisher Scientific, Inc.). When the cells reached $\sim 80 \%$ confluency, lentiviruses expressing different shRNAs targeting KLF4 mRNA were produced by co-transfecting the expression constructs with packaging plasmids, including $2.5 \mu \mathrm{g}$ of pMD2.G (cat. no. 12259; Addgene, Inc.), $3.75 \mu \mathrm{g}$ of pMDLg/pRRE (cat. no. 12251; Addgene, Inc.) and $3.75 \mu \mathrm{g}$ of pRSV-Rev (cat. no. 12253; Addgene, Inc.) into the 293T cells using the X-tremeGENE ${ }^{\mathrm{TM}}$ HP Transfection Reagent (Roche Diagnostics $\mathrm{GmbH}$ ). Supernatants were collected at 48 and $72 \mathrm{~h}$ after transfection and filtered through a $0.45-\mu \mathrm{m}$ membrane. The filtrates were concentrated using a Lenti-X Concentrator (Clontech Laboratories, Inc.) and centrifuged at $4^{\circ} \mathrm{C}, 1,500 \mathrm{x} \mathrm{g}$ for $1 \mathrm{~h}$. Lentiviral titers were measured by transducing the viruses into $293 \mathrm{~T}$ cells in the presence of $4.0 \mu \mathrm{g} / \mathrm{ml}$ polybrene (EMD Millipore) and were subsequently challenged by $2.0 \mu \mathrm{g} / \mathrm{ml}$ puromycin (Invitrogen; Thermo Fisher Scientific, Inc.) at $48 \mathrm{~h}$ post-transduction. A non-targeting control shRNA sequence (cat. no. SHC016V; EMD Millipore) served as a negative control (shNTC).

Erythroid cells from day 4 of culture were transduced overnight with the lentiviruses at a multiplicity of infection of 20 in the phase 2 medium supplemented with $8.0 \mu \mathrm{g} / \mathrm{ml}$ 
polybrene. Transduced cells were treated with $0.5 \mu \mathrm{g} / \mathrm{ml}$ puromycin at $48 \mathrm{~h}$ post-transduction and were consequently placed in the phase 3 medium at $48 \mathrm{~h}$ after puromycin selection.

Erythroid differentiation and morphology. Cultured cells $\left(5 \times 10^{4}\right.$ cells) were harvested on day 12 and resuspended in Dulbecco's phosphate-buffered saline (HyClone; Cytiva). Erythroid differentiation was surveilled using antibodies against two erythroid-specific surface markers, phycoerythrin-conjugated mouse monoclonal anti-human CD71 (cat. no. CY1G4; BioLegend, Inc.) and allophycocyanin-conjugated mouse monoclonal anti-human CD235a (cat. no. GA-R2; BD Biosciences). Flow cytometry was achieved on BD Accuri ${ }^{\mathrm{TM}}$ C6 Plus (BD Biosciences). Data were analyzed using FlowJo version 10.3.0 (FlowJo LLC). To investigate erythroid cell morphology, cultured cells $\left(5 \times 10^{4}\right.$ cells) were fixed with absolute methanol and subsequently stained with modified Giemsa stain (MilliporeSigma) according to the manufacturer's instructions. The stained cells were examined under a light microscope.

Reverse transcription-quantitative PCR (RT-qPCR). Total RNA was extracted from cultured cells $\left(1 \times 10^{6}\right.$ cells) on day 10 using the TRIzol ${ }^{\circledR}$ Reagent (Ambion; Thermo Fisher Scientific, Inc.) according to the manufacturer's instructions. The extracted RNA samples (1 $\mu \mathrm{g}$ each) were treated with DNase I (Thermo Fisher Scientific, Inc.) to remove DNA contamination and were reverse transcribed into cDNAs using a RevertAid First Strand cDNA Synthesis Kit (Thermo Fisher Scientific, Inc.) according to the manufacturer's instructions. RT-qPCR was performed in duplicate using gene-specific primers, as presented in Table SII and FastStart ${ }^{\mathrm{TM}}$ Essential DNA Green Master (Roche Diagnostics GmbH) according to the manufacturer's instructions. qPCR was performed and analyzed using a CFX96 Real-Time System (Bio-Rad Laboratories, Inc.) with pre-incubation at $95^{\circ} \mathrm{C}$ for $5 \mathrm{~min}$, followed by 35 cycles of denaturation at $95^{\circ} \mathrm{C}$ for $10 \mathrm{sec}$, annealing at $60^{\circ} \mathrm{C}$ for $10 \mathrm{sec}$ and $72^{\circ} \mathrm{C}$ for $10 \mathrm{sec}$. All target gene expression levels were normalized to $\beta$-actin $(A C T B)$ mRNA expression levels. Relative gene expression data were calculated using the $2^{-\Delta \Delta \mathrm{Cq}}$ method (20).

Western blot analysis. Nuclear and cytoplasmic proteins were extracted from a pellet of at least $5 \times 10^{6}$ cultured cells on day 10 using NE-PER ${ }^{\mathrm{TM}}$ Nuclear and Cytoplasmic Extraction Reagents (Thermo Fisher Scientific, Inc.) according to the manufacturer's instructions. The protein concentration was determined using the Quick Start ${ }^{\mathrm{TM}}$ Bradford Protein Assay (Bio-Rad Laboratories, Inc.) according to the manufacturer's instructions. A total of $10 \mu \mathrm{g}$ protein was run on $10 \%$ SDS-polyacrylamide gel, transferred to a polyvinylidene fluoride membrane and subsequently blocked at room temperature for $1 \mathrm{~h}$ with $5 \%$ skimmed milk in PBS supplemented with $0.05 \%$ Tween-20. Immunoblotting was performed by incubating the membranes with specific antibodies against their target proteins (Table SIII) at room temperature for $1 \mathrm{~h}$. The membrane was washed three times for $10 \mathrm{~min}$ each with blocking buffer. HRP-conjugated secondary antibodies were then added and incubated at room temperature for $1 \mathrm{~h}$ before signal development. Chemiluminescent detection was conducted with Amersham ${ }^{\mathrm{TM}}$ ECL $^{\mathrm{TM}}$ Prime Western Blotting
Detection Reagent (Cytiva) according to the manufacturer's instructions.

$H b$ typing. Hemolysates were prepared from a minimum of $1 \times 10^{6}$ cultured cells on day 14 and subjected to high-performance liquid chromatography for $\mathrm{Hb}$ type analysis using the Bio-Rad VARIANT II Hemoglobin Testing System with $\beta$-Thalassemia Short Program (Bio-Rad Laboratories, Inc.) according to the manufacturer's protocols.

Statistical analysis. Statistical analysis was performed using SPSS version 26.0.0.0 (IBM Corp.). Unpaired student's t-test and one-way ANOVA with Tukey's post hoc test were performed to identify significant differences. Data are presented as means \pm SEM and $\mathrm{P}<0.05$ was considered to indicate a statistically significant difference.

\section{Results}

KLF4 mRNA expression levels decrease in erythroid progenitor cells from fetal liver samples. Our previous study conducted microarray analysis using Affymetrix GeneChip ${ }^{\circledR}$ Human Gene 2.0 ST Arrays to differentiate $K L F$ expression patterns in erythroid progenitor cells from fetal liver and adult peripheral blood samples (19). According to the microarray data, KLF4 and KLF9 emerged as the top candidate genes due to their greater downregulation $(0.79$-fold; $\mathrm{P}=0.06495)$ and upregulation (1.91-fold; $\mathrm{P}=0.00628$ ), respectively, in fetuses when compared with adults (Table SIV). The mRNA expression levels of 18 human $K L F \mathrm{~s}$, along with the key $\mathrm{HbF}$ regulators, $B C L 11 A$ and $L R F$, and eight globin genes were subsequently validated by RT-qPCR using the existing cDNA samples obtained from our previous study (19). The results demonstrated that KLF4 mRNA expression was significantly downregulated $(0.32 \pm 0.08$-fold; $P=0.02413$; Fig. 1$)$, which was similar to that observed from the microarray data (Table SIV), whereas the upregulation of KLF9 mRNA expression was not detected by RT-qPCR. Instead, the mRNA expression of $K L F 7$ was significantly upregulated $(1.68 \pm 0.07$-fold; $\mathrm{P}=0.03000$; Fig. 1). However, certain $K L F$ expression patterns obtained from RT-qPCR, for example, undetectable levels of $K L F 8, K L F 12$ and KLF14 (Fig. 1) were inconsistent with the results from the microarray. The discrepancy of the association between results of the microarray and RT-qPCR could be due to different platform conditions. The mRNA expression levels of the two well-characterized $\mathrm{HbF}$ regulators, BCL11A and $L R F$ were also analyzed for their function as essential $H B G$ repressors $(3,4)$. Although the results demonstrated that the two were relatively decreased in fetuses when compared with the adults, only the mRNA expression level of BCL11A was significantly downregulated in the fetuses (Fig. S1). These results indicated that KLF4 mRNA expression might be developmentally regulated and associated with changes in fetal globin expression, concomitant with the BCL11A mRNA expression level.

KLF4 knockdown increases embryonic and fetal globin gene expression. To determine the effects of KLF4 on globin expression, the expression levels of eight human globin genes were examined using RT-qPCR following KLF4 knockdown 


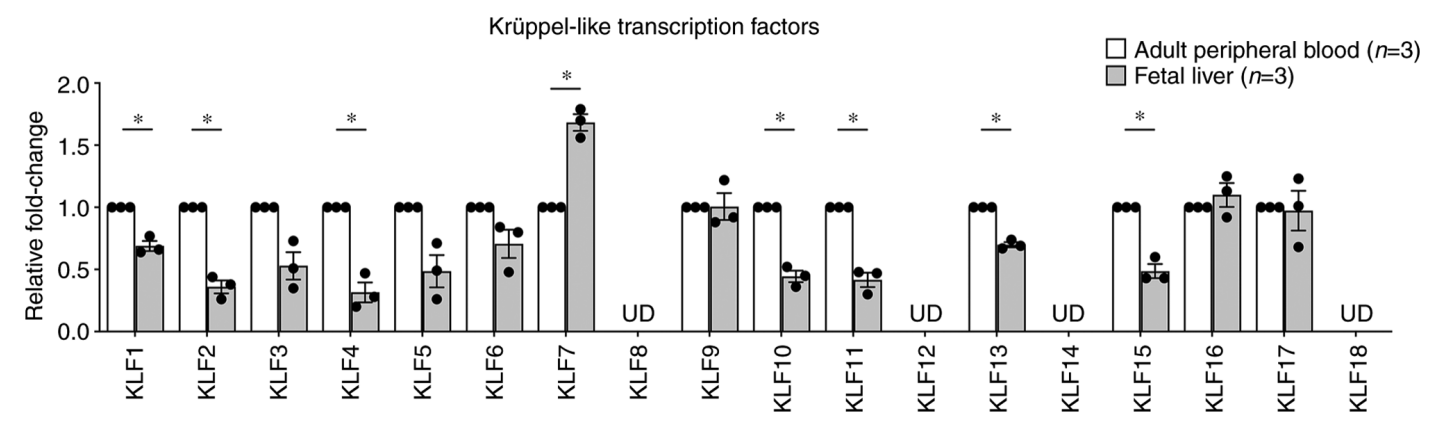

Figure 1. mRNA expression patterns of $18 K L F \mathrm{~s}$ in erythroid progenitor cells from FL and $\mathrm{AB}$ as examined by reverse transcription-quantitative PCR. Gene expression levels were normalized to $\beta$-actin. Data are presented as the means $\pm \mathrm{SEM}$ of relative fold-change of $\mathrm{FL}(\mathrm{n}=3)$ relative to $\mathrm{AB}(\mathrm{n}=3)$. ${ }^{*} \mathrm{P}<0.05 . K L F$, Krüppel-like factor; FL, fetal liver; AB, adult peripheral blood; UD, undetectable.

in human erythroid progenitor cells obtained from healthy individuals and donors with compound heterozygous $\beta^{0}$-thalassemia/HbE, which exhibit high baseline $\mathrm{HbF}$ levels. KLF4 expression was more pronounced upon erythroid maturation in the primary erythroid culture system (Fig. S2). KLF4sh1 and KLF4sh2 reduced the KLF4 expression levels by $>0.5$-fold when compared with shNTC. Furthermore, downregulation of KLF4 did not significantly affect the three known $\mathrm{HbF}$ suppressors, KLF1, BCL11A and LRF (Fig. 2A and B). The results revealed that downregulation of KLF4 in hematopoietic progenitor cells from healthy individuals and donors with $\beta^{0}$-thalassemia/HbE evidently upregulated $\zeta$-globin $(H B Z), \varepsilon$-globin $(H B E)$ and moderately increased $H B G$ mRNA expression when compared with shNTC in the two subject groups (Fig. 2C). This alteration was similar to that of globin mRNA expression patterns in hematopoietic progenitor cells from fetal liver samples (Fig. S1). In addition, marginally decreased expression levels of $\mu$-globin $(H B M)$, $\alpha$-globin $(H B A), \theta$-globin $(H B Q), \delta$-globin $(H B D)$ and $H B B$ genes were observed when compared with the control (Fig. 2C). The increase of $\mathrm{HbF}(\Delta \% \mathrm{HbF})$ executed by experimental KLF4sh1 knockdown in healthy and $\beta^{0}$-thalassemia/HbE erythroid cells was $2.0 \pm 0.8$ and $2.7 \pm 1.4 \%$, respectively, above the control. The $\Delta \% \mathrm{HbF}$ observed by experimental KLF4sh2 knockdown in healthy and $\beta^{0}$-thalassemia/HbE erythroid cells was $1.5 \pm 1.0$ and $5.0 \pm 1.3 \%$, respectively, above the control (Fig. S3). These changes in $\mathrm{HbF}$ levels were consistent with the marginally increased $H B G$ mRNA expression observed in Fig. 2C.

The effects of KLF4 knockdown on erythroid cell differentiation and maturation were assessed by evaluating the expression levels of two erythroid-specific surface markers, CD71 and glycophorin A (GPA), and by investigating erythroid morphology under a light microscope. Erythroid differentiation and gating proportions were analyzed based on the expression levels of CD71 and GPA, as follows: R1, CD71 $1^{\text {high }} / \mathrm{GPA}^{\text {low }} ; \mathrm{R} 2, \mathrm{CD} 71^{\text {high }} / \mathrm{GPA}^{\text {high }}$; R3, $\mathrm{CD} 1^{\text {medium }} / \mathrm{GPA}^{\text {high. }}$; and R4, CD71 1ow/GPA ${ }^{\text {high }}$ (Fig. 2D). In the culture system, $\beta^{0}$-thalassemia/HbE-derived erythroblasts demonstrated delayed erythroid differentiation when compared with the healthy erythroblasts (Fig. 2E and F). Downregulation of KLF4 in healthy erythroblasts using KLF4sh1 did not affect erythroid differentiation or maturation. However, KLF4sh2 knockdown in the healthy group insignificantly delayed erythroid differentiation as demonstrated by the reduction in the R4 portion when compared with the controls (Fig. 2F). Similar findings of the fairly delayed differentiation were also observed in the $\beta^{0}$-thalassemia/HbE-derived erythroblasts with KLF4sh2 knockdowns, in which the majority of the cell populations retained in R2 (Fig. 2F). Early-stage erythroid morphology was found in experimental KLF4sh2 knockdown in both healthy and $\beta^{0}$-thalassemia/HbE-derived erythroblasts when compared with the controls (Fig. 2E), confirming a slightly delayed erythroid maturation. Notably, modest promotion of cell differentiation was apparent in $\beta^{0}$-thalassemia/HbE-derived erythroblasts upon KLF4sh1 knockdown as evidenced by the increase of R4 when compared with the controls (Fig. 2F). Following KLF4sh1 knockdown, erythroid morphology accelerated erythroid maturation in $\beta^{0}$-thalassemia/HbE-derived erythroblasts when compared with the controls (Fig. 2E). However, this acceleration was not particularly noticeable in healthy subjects under the same circumstances.

\section{Discussion}

$\mathrm{Hb}$ switching is specific to human developmental stages, resulting in the production of different $\mathrm{Hb}$ molecules during ontogeny (1). However, the mechanisms underlying the switch remain unclear. KLFs are transcription factors classified by highly conserved three $\mathrm{Cys}_{2} \mathrm{His}_{2}$ zinc finger DNA binding domains at the $\mathrm{C}$ terminus $(8-10)$. KLFs bind to a specific CACCC DNA motif, which are commonly found within human globin gene promoters $(7,11,12)$. KLF1 is a member of the KLF family, regulating fetal to adult $\mathrm{Hb}$ switching by activating the expression of the major $H B G$ repressor, BCL11A. Furthermore, KLF1 can dock on the CACCC boxes within the $H B B$ gene promoter and can further activate $H B B$ gene expression. Notably, the amino acid sequences of KLF1 are markedly similar to those of KLF2 and KLF4 (13). This similarity may indicate comparable functions between KLF1, KLF2 and KLF4 in relation to globin gene regulation.

In the present study, the mRNA expression pattern of 18 human $K L F$ s in fetal and adult erythroblasts were investigated using RT-qPCR. The expression of KLF4 was revealed to be the most significantly downregulated in erythroid progenitor cells from the fetal liver when compared with those from adults. The result was consistent with our previously reported microarray data (19). This indicates that KLF4 

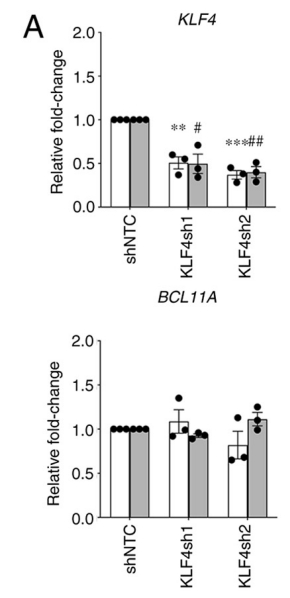

C

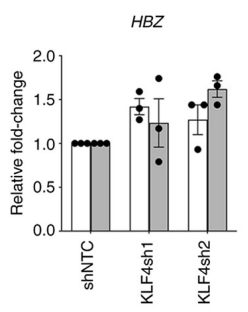

HBE

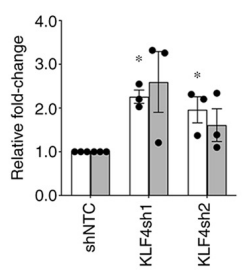

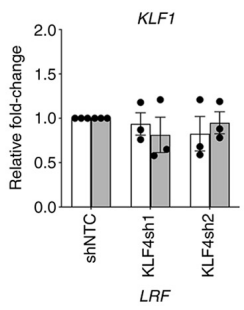

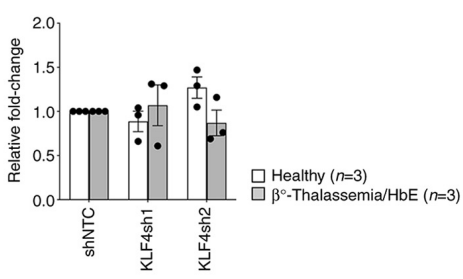

$H B M$

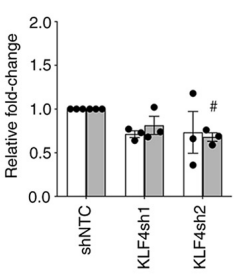

$H B G$

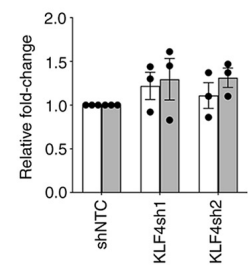

$H B A$

$H B D$
B
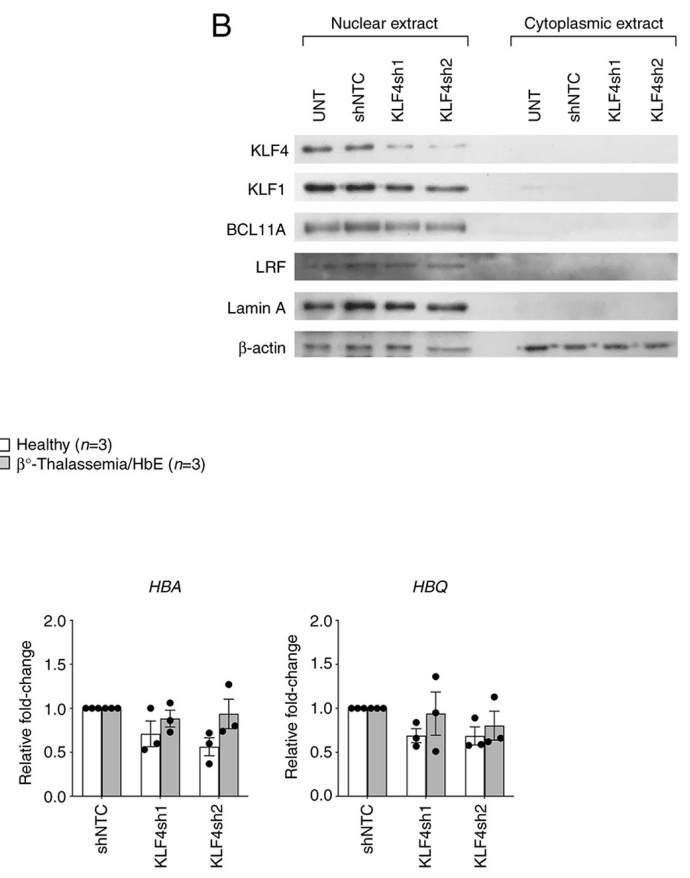

$H B B$
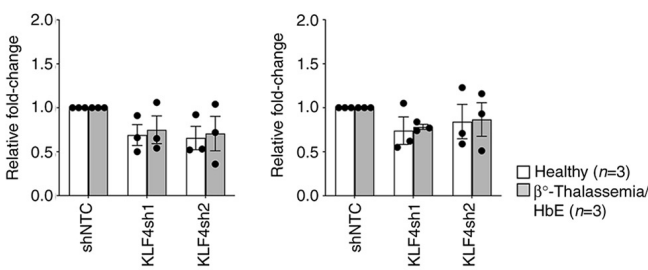

$\mathrm{E}$
D

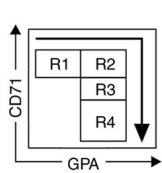

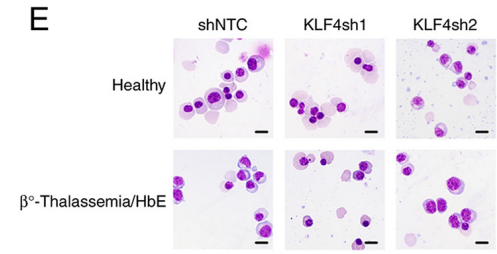

$\mathrm{F}$

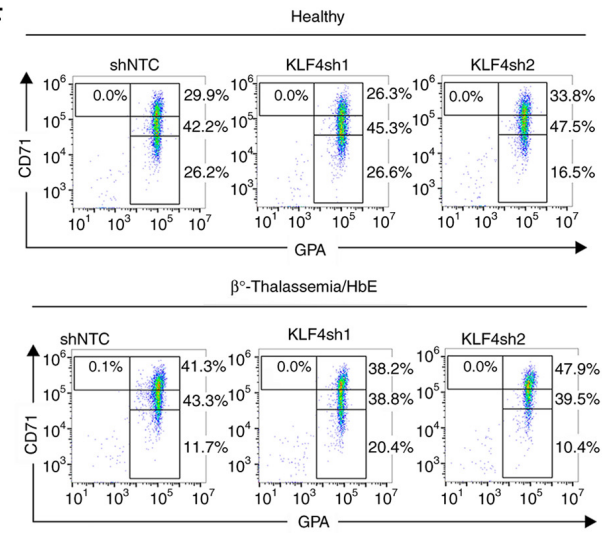

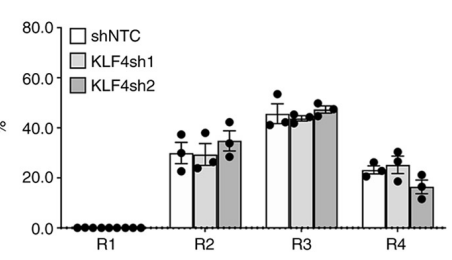

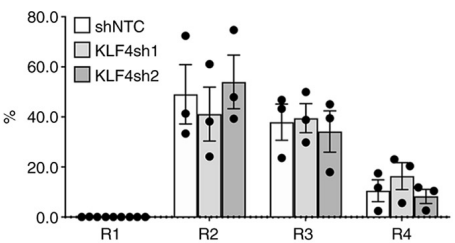

Figure 2. Effects of KLF4 knockdown in erythroid progenitor cells from healthy individuals and patients with $\beta^{0}$-thalassemia/HbE. (A) RT-qPCR demonstrating KLF4 knockdown efficiency and effects on KLF1, BCL11A and $L R F$ mRNA expression levels. (B) Representative western blot analysis showing KLF4 knockdown efficiency and effects on KLF1, BCL11A and LRF protein expression levels. Lamin A and $\beta$-actin served as loading controls for nuclear and cytoplasmic protein origin, respectively. (C) RT-qPCR displaying relative fold-change of $\alpha$-like globin (upper panel) and $\beta$-like globin (lower panel) mRNA expression levels. Relative fold-change represents the mRNA expression levels normalized to $\beta$-actin of shRNAs targeting KLF4 (KLF4sh1 and KLF4sh2) vs. shNTC. Data are presented as the means \pm SEM of healthy individuals $\left(n=3 ;{ }^{*} \mathrm{P}<0.05,{ }^{* *} \mathrm{P}<0.005,{ }^{* * * *} \mathrm{P}<0.0005\right)$ and patients with $\beta^{0}$-thalassemia/HbE $(\mathrm{n}=3$; $\left.{ }^{\#} \mathrm{P}<0.05,{ }^{\# \#} \mathrm{P}<0.005\right)$. (D) Illustrative flow cytometric analysis on the basis of transferrin receptor, CD71 and GPA expression levels. Where R1=CD71 high/GPA ${ }^{\text {low}}$; $\mathrm{R} 2=\mathrm{CD} 71^{\text {high }} / \mathrm{GPA}^{\text {high }} ; \mathrm{R} 3=\mathrm{CD} 71^{\text {medium }} / \mathrm{GPA}^{\text {high }}$; and R4=CD71 low $/ \mathrm{GPA}^{\text {high }}$. (E) Representative cytospin preparations of modified Giemsa-stained cells on day 12 visualized under a light microscope (x1,000 magnification; scale bar, $10 \mu \mathrm{m}$ ). (F) Representative flow cytometric analysis of experimental KLF4 knockdown. The bar graph represents proportions of each cell population. KLF, Krüppel-like factor; HbE, hemoglobin E; RT-qPCR, reverse transcription-quantitative PCR; BCL11A, B-cell lymphoma/leukemia 11A; LRF, leukemia/lymphoma-related factor; shRNA, short hairpin RNA; shNTC, non-targeting control shRNA; GPA, glycophorin A; $H B Z, \zeta$-globin; $H B M, \mu$-globin; $H B A, \alpha$-globin; $H B Q, \theta$-globin; $H B E$, $\varepsilon$-globin; $H B G, \gamma$-globin; $H B D, \delta$-globin; $H B B, \beta$-globin. 
might be developmentally controlled. Furthermore, the lower mRNA expression level of KLF4 was concomitant with the greater mRNA expression levels of embryonic and fetal globin, including $H B Z, H B E$ and $H B G$. This result revealed the association between the modest expression of the KLF4 mRNA level and the pronounced mRNA expression levels of embryonic and fetal globin in erythroid progenitor cells from the fetus. However, it was found that the mRNA levels of two major $H B G$ gene repressors, $K L F 1$ and BCL11A were significantly downregulated in the fetus group when compared with the adult group. Therefore, the elevation of fetal globin mRNA expression in the present study might be due to the reduction of these two transcription factors.

To elaborate on the function of KLF4 on globin expression regulation at diverse $\mathrm{HbF}$ baseline levels, lentiviral shRNA-mediated KLF4 knockdowns were performed in erythroid progenitor cells from healthy adults and patients with $\beta^{0}$-thalassemia/HbE. The results demonstrated that experimental KLF4 knockdown could induce embryonic (HBZ and $H B E)$ and fetal $(H B G)$ globin mRNA expression in healthy subjects and those with $\beta^{0}$-thalassemia/HbE. Moreover, a marginal surge in the $\mathrm{HbF}$ level also corresponded with the modest elevated $H B G$ mRNA expression. However, these findings were inconsistent with previous studies showing that KLF4 triggers $H B G$ and $H B A$ gene expression in human erythroid cells and the K562 cell line, respectively $(16,17)$. This may be due to the disparate erythroid cell stage during experimental KLF4 knockdown and the dissimilar erythroid culture system. Notably, downregulation of KLF4 did not significantly affect the expression levels of well-known fetal globin gene repressors, KLF1, BCL11A and LRF, suggesting a possible independent globin regulation mechanism. Although KLF4 knockdown revealed insignificant effects on erythroid cell maturation, delayed erythroid differentiation was observed in subjects with $\beta^{0}$-thalassemia/HbE when compared with the healthy subjects. To date, the effort to induce embryonic $H B Z$ expression in patients with $\alpha$-thalassemia major (ATM) has been proposed as a novel therapy to improve the phenotype and survival rate of patients with ATM (21). Therefore, manipulations of KLF4 expression using chemical compounds or molecular approaches may also be considered as potential therapeutic strategies for $H B A$ substitution via $H B Z$ induction in those patients.

Thus, the present study revealed that the KLF4 mRNA expression level is relatively downregulated in hematopoietic progenitor cells from the fetal liver. Additionally, experimental knockdown of KLF4 promoted embryonic and fetal globin mRNA expression in human hematopoietic progenitor cells. Despite a small sample size, this evidenced the inverse association between KLF4 and embryonic and fetal globin mRNA expression in human erythroid progenitor cells. Moreover, the development of drugs or molecular methods that reduce KLF4 and further increase embryonic globin gene expression for adult globin substitution may provide an alternative treatment for severe $\alpha$-thalassemia.

\section{Acknowledgements}

The authors would like to thank Miss Thongperm Munkongdee, Miss Nattrika Buasuwan and Miss Nurmeeha Hinna,
Thalassemia Research Center, Institute of Molecular Biosciences, Mahidol University (Nakhon Pathom, Thailand) for their assistance with evaluating DNA for thalassemia and hemoglobin analyses. The authors would also like to thank Associate Professor Alisa Tubsuwan (Stem Cell Research Unit, Institute of Molecular Biosciences, Mahidol University) who provided resources for lentivirus production.

\section{Funding}

The present study was supported by a grant from the Faculty of Allied Health Sciences, Thammasat University (grant no. 1/2562; Pathum Thani).

\section{Availability of data and materials}

The datasets used and/or analyzed during the current study are available from the corresponding author on reasonable request.

\section{Authors' contributions}

PK conceptualized the idea, designed the research, performed experiments, analyzed data and wrote the manuscript. NJ performed erythroid culture and supplied resources. AT and SH provided microarray data, analyzed microarray data and supplied cDNA samples. PK and AT confirm the authenticity of all the raw data. All authors read and approved the final manuscript.

\section{Ethics approval and consent to participate}

The study procedures were approved in accordance with compliance to the Declaration of Helsinki, The Belmont Report, Council for International Organizations of Medical Sciences guidelines and the International Conference on Harmonisation-Good Clinical Practice by the Ethical Review Sub-Committee Board for Human Research Involving Sciences (Thammasat University, Pathum Thani, Thailand; approval nos. 198/2561 and 031/2563). In our previous study (19), women who underwent pregnancy termination due to medical complication provided written informed consent to donate their fetus for research purposes. The protocols for the previous study were approved in accordance with the Declaration of Helsinki by the Committee on Human Rights related to research involving human subjects (Faculty of Medicine, Ramathibodi Hospital, Mahidol University, Bangkok, Thailand; Institutional Review Board no. MURA2013/363).

\section{Patient consent for publication}

Not applicable.

\section{Competing interests}

The authors declare that they have no competing interests.

\section{References}

1. Weatherall DJ and Clegg JB: The Thalassaemia Syndromes. 4th edition. Blackwell Science, Oxford, 2008. 
2. Zhou D, Liu K, Sun CW, Pawlik KM and Townes TM: KLF1 regulates BCL11A expression and gamma- to beta-globin gene switching. Nat Genet 42: 742-744, 2010.

3. Sankaran VG, Menne TF, Xu J, Akie TE, Lettre G, Van Handel B, Mikkola HK, Hirschhorn JN, Cantor AB and Orkin SH: Human fetal hemoglobin expression is regulated by the developmental stage-specific repressor BCL11A. Science 322: 1839-1842, 2008.

4. Masuda T, Wang X, Maeda M, Canver MC, Sher F, Funnell AP, Fisher C, Suciu M, Martyn GE, Norton LJ, et al: Transcription factors LRF and BCL11A independently repress expression of fetal hemoglobin. Science 351: 285-289, 2016.

5. Magor GW, Tallack MR, Gillinder KR, Bell CC, McCallum N, Williams B and Perkins AC: KLF1-null neonates display hydrops fetalis and a deranged erythroid transcriptome. Blood 125: 2405-2417, 2015.

6. Norton LJ, Funnell APW, Burdach J, Wienert B, Kurita R, Nakamura Y, Philipsen S, Pearson RCM, Quinlan KGR and Crossley M: KLF1 directly activates expression of the novel fetal globin repressor ZBTB7A/LRF in erythroid cells. Blood Adv 1: 685-692, 2017.

7. Borg J, Papadopoulos P, Georgitsi M, Gutiérrez L, Grech G, Fanis P, Phylactides M, Verkerk AJ, van der Spek PJ, Scerri CA, et al: Haploinsufficiency for the erythroid transcription factor KLF1 causes hereditary persistence of fetal hemoglobin. Nat Genet 42: 801-805, 2010.

8. Pollak NM, Hoffman M, Goldberg IJ and Drosatos K: Krüppel-like factors: Crippling and un-crippling metabolic pathways. JACC Basic Transl Sci 3: 132-156, 2018.

9. Pei J and Grishin NV: A new family of predicted Krüppel-like factor genes and pseudogenes in placental mammals. PLoS One 8: e81109, 2013

10. McConnell BB and Yang VW: Mammalian Krüppel-like factors in health and diseases. Physiol Rev 90: 1337-1381, 2010.

11. Cao A and Moi P: Regulation of the globin genes. Pediatr Res 51: 415-421, 2002.

12. Raich N and Romeo PH: Erythroid regulatory elements. Stem Cells 11: 95-104, 1993.
13. Chen X, Whitney EM, Gao SY and Yang VW: Transcriptional profiling of Krüppel-like factor 4 reveals a function in cell cycle regulation and epithelial differentiation. J Mol Biol 326: 665-677, 2003.

14. Basu P, Morris PE, Haar JL, Wani MA, Lingrel JB, Gaensler KM and Lloyd JA: KLF2 is essential for primitive erythropoiesis and regulates the human and murine embryonic beta-like globin genes in vivo. Blood 106: 2566-2571, 2005.

15. Vinjamur DS, Wade KJ, Mohamad SF, Haar JL, Sawyer ST and Lloyd JA: Krüppel-like transcription factors KLF1 and KLF2 have unique and coordinate roles in regulating embryonic erythroid precursor maturation. Haematologica 99: 1565-1573, 2014.

16. Kalra IS, Alam MM, Choudhary PK and Pace BS: Krüppel-like factor 4 activates HBG gene expression in primary erythroid cells. Br J Haematol 154: 248-259, 2011.

17. Marini MG, Porcu L, Asunis I, Loi MG, Ristaldi MS, Porcu S, Ikuta T, Cao A and Moi P: Regulation of the human HBA genes by KLF4 in erythroid cell lines. Br J Haematol 149: 748-758, 2010.

18. Gardiner MR, Gongora MM, Grimmond SM and Perkins AC: A global role for zebrafish klf4 in embryonic erythropoiesis. Mech Dev 124: 762-774, 2007.

19. Tangprasittipap A, Kaewprommal P, Sripichai O, Sathirapongsasuti N, Satirapod C, Shaw PJ, Piriyapongsa J and Hongeng S: Comparison of gene expression profiles between human erythroid cells derived from fetal liver and adult peripheral blood. PeerJ 6: e5527, 2018.

20. Livak KJ and Schmittgen TD: Analysis of relative gene expression data using real-time quantitative PCR and the 2(-Delta Delta C(T)) method. Methods 25: 402-408, 2001.

21. Gregory GL, Wienert B, Schwab M, Lianoglou BR, Hollis RP, Kohn DB, Conklin BR and MacKenzie TC: Investigating zeta globin gene expression to develop a potential therapy for alpha thalassemia major. Blood 136 (Suppl 1): S3-S4, 2020. 